\title{
НАУКА КАК ОБЩЕСТВЕННОЕ ЯВЛЕНИЕ: ОПРЕДЕЛЕНИЕ НАУКИ И СОЦИАЛЬНЫЙ ХАРАКТЕР ДЕЯТЕЛЬНОСТИ УЧЕНЫХ
}

\author{
B. С. Ткачев \\ Байкальский государственный университет, г. Иркутск, Российская Федерация
}

Информация о статье

Дата поступления

13 июня 2017 г.

Дата принятия к печати 30 июня 2017 г.

Дата онлайн-размещения 15 сентября 2017 г.

\section{Ключевые слова}

Определение науки; знание; познание; научное знание; понятийное мышление; производство нового знания; производство старого знания; наука как общественное явление; социальный характер деятельности ученых

\begin{abstract}
Аннотация
В статье осуществляется методологический анализ науки как общественного явления. Доказывается, что наука не может быть уделом талантливых, гениальных и высоконравственных одиночек, поскольку производство знания является массовым, ведется многочисленными его участниками; понимание науки не должно сводиться исключительно к творческой деятельности ученых, так как в определенные периоды общественной жизни объем «бюрократических» процедур возрастает и начинает превышать объем творческой составляющей научного производства. Указывается также на недостаточность определения науки как деятельности ученых, направленной на выработку и теоретическую систематизацию знаний о мире: наука не упразднила производство знания, осуществляемого другими фрормами духовного производства, а лишь добавила к ним новый элемент - производство знания в понятийной форме. В статье акцентируется внимание на том, что эффрективное использование ресурсов знания немыслимо без освоения возможностей, скрытых в трудах современных ученых, но оно еще более немыслимо без творческого осмысления трудов их ближайших и отдаленных предшественников, поэтому в истории и философии науки важно осознать не только открытие, которое было получено в результате научной деятельности, но и путь, который привел к данному открытию. Именно осознание пути и обнаруживает ранее неиспользуемые идеи и темы, активно циркулирующие в прошлом и незримо руководящие направленностью изысканий современных ученых. В статье рассматривается также один из способов оценки общественного смысла науки и деятельности ученых.
\end{abstract}

\section{SCIENCE AS A SOCIAL PHENOMENON: DEFINITION OF SCIENCE AND SOCIAL CHARACTER OF SCIENTIFIC ACTIVITY}

\author{
Valerii S. Tkachev \\ Baikal State University, Irkutsk, Russian Federation
}

\section{Article info}

Received

June 13, 2017

Accepted

June 30, 2017

Available online

September 15, 2017

\section{Keywords}

Definition of science; knowledge; cognition; scientific knowledge; conceptual thinking; generation of new knowledge; generation of old knowledge; science as a social phenomenon; social character of scientific activity

\section{Abstract}

A methodological analysis of science as a social phenomenon is performed in the given research paper. It is demonstrated that science cannot be regarded as a domain of individual geniuses of good morals as generation of knowledge is global, numerous participants contributing to it. Understanding of science should not be limited to a creative activity of scholars because, at some phases of social life, the amount of «paperwork» grows to exceed the creative part in the scientific production. The author suggests that the definition of science as an activity carried out by scholars in order to generate some knowledge about the world and theoretically organize it is insufficient as soon as science does not eliminate generation of knowledge by other forms of intellectual production but adds a new way of knowledge generation, i.e. in the conceptual form. Resources of knowledge cannot be used efficiently if opportunities hidden in works of contemporary scientists are neglected but the author turns the spotlight on the idea that, for knowledge be used in an efficient manner, it is essential to give a creative interpretation to scientific works of both immediate and remote predecessors; thus, a way a scientific discovery is made rather than only a discovery itself as a result of the scientific activity is to be 
recognized by the history and philosophy of science. It is the recognition of the discovery way that reveals unused ideas and subjects that were widely discussed in the past and covertly guide researchers in their work in the present. One of the ways of determining the social value of science and scientists' work is also considered in the research paper.

\section{1. Недостатки современных определений науки}

К настоящему времени написано немало книг, где рассматривается понятие науки. И все же вопрос о ее сущности остается дискуссионным. Наиболее распространены три определения науки. Первое ориентирует на то, чтобы представить науку как деятельность исключительно талантливых, гениальных и высоконравственных одиночек. Но такое определение недостаточно.

Наука не может быть уделом талантливых, гениальных и высоконравственных одиночек; она является производством знания, а знания добываются усилиями многочисленных участников духовного производства. Современное производство знания относится к числу массовых производств, и носителям таких производств «ничто человеческое не было чуждо».

Приведем примеры из истории науки. Платон ненавидел Демокрита до такой степени, что сжигал его рукописи.

Тихо Бра́ге (1546-1601) - датский астроном, имел дурной характер, любил алкоголь и, выпивая, становился заурядным драчуном. В одной из драк ему отхватили ножом полноса, и оставшуюся жизнь он носил специальную повязку.

Фрэнсис Бэкон (1561-1626) - английский философ; в художественной прозе проявил себя как писатель-моралист. Он написал «Опыты, или Наставления нравственные и политические» (1625), сборник эссе «О мудрости древних» (1609), но в частной жизни совсем не являлся «святошей». Молва гласит, что он не чурался брать взятки и однажды был обвинен и приговорен к денежному штрафу в 40 тыс. ффунтов [1, с. 70-71].

Исаак Ньютон (1643-1727) - английский ученый, в 1687 г. издал труд «Математические начала натуральной философии», в котором сфрормулировал закон всемирного тяготения. Известно, что открытие этого закона относится к числу наиболее значительных достижений своего времени. Оно было восторженно встречено не только научным сообществом, но и политической элитой общества. Ньютона избрали в английский парламент, а затем в Парижскую королевскую академию естественных наук, его возвели в должность президента Лондонского королевского общества (академии наук), назна- чили смотрителем Монетного двора и даже посвятили в рыцари. Однако стремительная карьера Ньютона, как оказалось, определялась не только его научными заслугами, но и случайными, весьма пикантными обстоятельствами. Об этих обстоятельствах и поведал в свое время Франсуа Вольтер, известный просветитель XVIII в.

«В молодости моей, - писал он в «Философрских письмах», - я полагал, что Ньютон составил себе состояние благодаря своим исключительным заслугам. Я воображал, что двор и Лондон без голосования признали его главным смотрителем королевского Монетного двора. Ничуть не бывало. Исаак Ньютон имел хорошенькую племянницу, прозванную «Мадам Кондюит». Она очень нравилась великому казначею Галифаксу. Исчисление бесконечно малого и гравитация ничего не дали бы Ньютону, не будь у него красивой племянницы» [1, с. 75].

Нечто подобное в поведении можно обнаружить и в среде русских и даже советских ученых, деятельность которых относилась к более поздним временам существования науки и складывалась при иных понятиях нравственной жизни [2].

Второе определение науки акцентирует внимание на том, что она является творческой деятельностью ученых по получению нового знания о мире. Но и это определение науки недостаточно. Конечно, наука не обходится без творческой деятельности ученых, и креативность в ряде случаев достаточно значительна в общем объеме выполняемых ими работ, однако всю науку в целом никак нельзя свести исключительно к творческой деятельности.

Во-первых, с усложнением современной науки растет объем черновой работы, направленной на добывание научных фрактов. Оно никак не может обходится без таких рутинных дел, как решение повседневных организационно-научных, административных и фринансовых задач, а поскольку эти задачи приходятся на разные периоды существования науки, колеблется и объем «бюрократических» процедур: в динамичные эпохи их доля, разумеется, уменьшается, а в застойные - увеличивается иногда настолько, что может значительно превысить объем творческой составляющей в деятельности ученых. 
Во-вторых, носители науки тратят время не только на производство нового знания, но и на сохранение старого. В свое время геометрия Лобачевского (1826), геометрия Римана (1854), фрактальная геометрия (1977) совершили перевороты в представлениях людей о пространстве. Естественно, что они требовали времени для освоения их практической значимости. Но не меньшие усилия понадобились и для осмысления теоретического наследия прошлого - проективной, аналитической, дифференциальной форм геометрии, не говоря уже о геометрии Евклида, которая перед этим господствовала в науке более двух тысяч лет и служила основой построения всей евклидовой картины мира, образцом применения аксиоматического метода. И такое распределение труда ученых исторически справедливо в отношении как прошлого, так и современного состояния науки, что вполне объяснимо.

Эфрфективное использование ресурсов знания немыслимо без освоения возможностей, скрытых в трудах современных ученых, но оно еще более немыслимо без творческого осмысления трудов их ближайших и отдаленных предшественников [3].

Так, еще некоторое время назад считалось, что закон всемирного тяготения был открыт Ньютоном чисто случайно. Но, как выяснилось позже, открытие закона было достаточно подготовлено усилиями его предшественников. Из истории науки известно, что идея данного закона пробивала себе дорогу в работах Г. Галилея, Х. Гюйгенса, А. Борелли, Р. Гука, У. Гильберта, И. Буйяра. Но дело еще и в том, что научный смысл работ названных авторов, включая работы самого Ньютона, невозможно понять, не имея представлений об особенностях развития античной науки.

То же самое можно сказать о научных заслугах И. Кеплера. Этого ученого «обычно считают ниспровергателем старой картины мира, но на самом деле он во многом использовал созданную Аристотелем физику. Он, как и Аристотель, полагал, что движение планет должно быть круговым (совершенным), и поэтому рассчитывал видимое движение планет с помощью сложной системы эпициклов. И лишь позднее, особенно после Галилея, его теория оказалась переворотом, знаменующим собой решительный разрыв с птолемеевой космологией» [1, с. 128].

О тонкостях данной проблемы очень точно высказался историк математики Ван дер Варден. «Ньютон, - писал он, - ничего не творил из ничего. Без огромных трудов Птолемея, дополнившего и завершившего ан- тичную астрономию, была бы невозможна и «Новая астрономия» Кеплера, а вслед за ней и механика Ньютона. Без конических сечений Аполлония, которые Ньютон знал в совершенстве, точно так же был бы немыслим и закон тяготения. И интегральное исчисление Ньютона можно понять только как развитие архимедовых методов для определения площадей и объемов. История механики как точной науки начинается только с установления закона рычага, определения направленного вверх давления воды и нахождения центров тяжести у Архимеда» [4, с. 53-54; 5-8].

Приведенные рассуждения подводят к мысли, что в истории и философии науки важно осознать не только результат научной деятельности, но и путь, который привел к данному результату. Само по себе открытие доказывает, что его автор, без сомнения, стоит «на плечах» своих предшественников, а с другой стороны, он обнаруживает ранее неиспользуемые идеи и темы, активно циркулирующие в прошлом. Именно идеи и темы прошлого незримо руководят направленностью современных изысканий. И это понятно. Старые знания зажаты границами прошлых эпох, а современные знания взламывают эти границы и как бы выпускают старые знания в новый свет. При этом старые знания решительно переосмысливаются, они незаметно обогащаются такими значениями, благодаря которым обретают новую форму, перестают быть тем, чем они были не только в глазах своих современников, но и самих создателей.

В качестве примера укажем на судьбу квантовой теории. Известно, что квантовую теорию Макс Планк предложил еще в 1900 г., но она противоречила идеям предшествующей физики и не могла быть оценена по достоинству. Лишь с выходом в свет трудов Эйнштейна (с 1905 г.) и Бора (в 1913 г.) эта теория заняла адекватное положение в науке [1, с. $129 ; 9$, с. 89-137; 10, с. 8-9].

Рассуждая о соотношении практического опыта прошлого и настоящего, обычно говорят, что в «настоящее» включается не все «прошлое», а только та его часть, которая подготовлена к функционированию на основе «настоящего», остальное же разрушается, забывается, становится ненужным и т. д. [11, с. 242-245]. И это действительно так. В свою очередь, не весь накопленный веками опыт человечества переходит в непосредственное бытие общества: основная его доля оказывается не в актуальном, а в потенциальном существовании. То, что накоплено в опыте, но не используется в настоящее время, должно рассматриваться как резервуар 
не полностью исчерпанных человеческих возможностей.

То же самое и в науке. Современное знание включает в себя знания прошлых эпох. Однако нельзя думать, что современное знание втягивает в себя всю совокупность прошлого знания. Часть старого знания подвергается разрушению, но к этому процессу подключается меньшая часть старого знания, а не бо́льшая. Отвергается то, что мешает развитию современного на тот период знания. И если воспользоваться образным выражением А. А. Любищева, то можно сказать, что «прошлое науки не кладбище с могильными плитами над навеки похороненными заблуждениями, а собрание недостроенных архитектурных ансамблей, многие из которых были не закончены не из-за порочности замысла, а из-за несвоевременности рождения проекта или из-за чрезмерной самоуверенности строителей» [12].

Необходимо обратить внимание и на то, что процесс выработки новых знаний не всегда одинаков. Новое знание производится разными способами, при этом способы определяются не только научными потребностями, но и особенностями общественного развития, в том числе скоростью их внедрения. «Ученым, - пишет М. Томпсон, - постоянно приходится иметь дело сразу с несколькими различными теориями, касающимися какой-то отдельной области знаний, одна из которых может казаться более подходящей или объемлющей по сравнению с другими. Иногда выдвинутая теория не слишком быстро продвигается вперед, так как еще требуется выполнить определенную работу, способствующую пониманию ее важности» [1, с. 129]. Так что одна и та же теория, функционируя в разных странах, может одновременно соответствовать требованиям одного общества и не соответствовать требованиям другого, она может ускорять и тормозить развитие общества, формировать и разрушать общественное и индивидуальное сознание.

В качестве примера укажем на историю европейской науки первой трети XIXв., когда актуализировался вопрос о природе науки.

На этот раз понимание науки сдвинулось к признанию внутреннего единства научной и образовательной деятельности. Застрельщиками такой трактовки оказались ученые из Германии. Они сделали ставку на университеты и исследовательские лаборатории, при этом особое внимание уделяли проблемам, имеющим прикладное значение, привлечению к своей работе студентов. Ученые из Англии и Франции поначалу отвергли «немец- кую модель» науки и образования, но вскоре вынуждены были признать ее; они поняли, что отказ оборачивается общим культурным отставанием своих стран и потерей лидерства в европейской науке.

Подобные факты позволяют говорить о том, что сложность вопроса о науке как творческой деятельности заключается В направлениях ее развития. Эти направления имеют исторически изменчивые и подвижные границы, они-то и оказываются трудно уловимыми для конкретной оценки творческости труда ученых.

Третье определение гласит, что наука представляет собой деятельность ученых, направленную на выработку и теоретическую систематизацию знаний о мире [13, с. 863-864]. Но и это определение науки имеет свои недостатки.

В определении науки употреблено понятие «знание», а оно тесно переплетается с двумя другими понятиями - «познание» и «научное знание».

Чтобы ответить на вопрос, что такое «знание», надо сравнить все три понятия, а затем решить, на чем сосредоточивает внимание наука - на «знании» или на «научном знании».

Познание - процесс приобретения знаний о свойствах мира, а знание - конечный результат познания. В ходе развития общественной жизни познание распадается на материальное и духовное познание $[14$, с. 30], а знание - на опытное, литературное, художественное, научное и философрское. И хотя все они связаны между собой генетическим родством (вытекают из потребности человека знать мир), тем не менее не тождественны друг другу. С этой точки зрения познание некорректно сводить к материальному или духовному познанию, так как то и другое единый процесс приобретения знания. В свою очередь, было бы некорректно сводить знание только к литературному, художественному, фрилософскому или научному, так как все они составляют единую систему знания о мире. Появление научного знания не упразднило другие формы знания, но добавило к ним элемент, сложившийся преимущественно в понятийной форме. С этого момента система знаний, ффункционирующих вне понятийной формы мышления (равно как разрозненных опытных сведений), перестала считаться научным знанием, а определение науки как единственной деятельности, направленной на выработку и теоретическую систематизацию знаний о мире, - корректным.

Как видим, все три определения науки (как по отдельности, так и в совокупности) недо- 
статочны по многим и очень важным критериям. Естественно, что неопределенность понимания природы науки порождает множество проблем. Одна из них - об общественном смысле науки и деятельности ученых.

\section{2. Общественный смысл науки и деятельности ученых}

Технику создают ученые, и люди уверены в том, что она предназначена для облегчения их труда: вряд ли кто сомневается в том, что стиральная машинка-автомат облегчает труд домохозяйки, а комбайн труд крестьянина и т. д.

Не сомневался в этом когда-то и Фрэнсис Бэкон, он был даже уверен, что можно изготовить машины и извлечь из них пользу в интересах людей.

Но вот Джон Стюарт Милль (1806-1873) и Карл Маркс (1818-1883) относились к машинам отрицательно, несмотря на то что Милль был теоретиком буржуазной, а Маркс пролетарской политэкономии.

«Сомнительно, - говорил Д. С. Милль в "Основаниях политической экономии", чтобы все сделанные до сих пор механические изобретения облегчили труд хотя бы одного человеческого существа» [15, с. 382].

И к такой оценке охотно присоединился К. Маркс. В гл. 13 «Капитала», посвященной машинам и крупной промышленности, основанной на применении машин, он пишет: «Миллю следовало бы сказать: "хотя бы одного человеческого существа, не живущего чужим трудом", потому что машины, несомненно, сильно увеличили число знатных бездельников... Но перед капиталистически применяемыми машинами вовсе и не ставится такой цели. Подобно всем другим методам развития производительной силы труда, они должны удешевлять товары, сокращать ту часть рабочего дня, которую рабочий употребляет на самого себя, и таким образом удлинять другую часть его рабочего дня, которую он даром отдает капиталисту. Машины - средство производства прибавочной стоимости» [там же].

Почему так? Бэкон признавал возможность изготовления машин «для людей» в XVI-XVII вв. , когда машинная эпоха еще только-только нарождалась, а Милль и Маркс давали оценку машинной эпохе в XIX в., когда она достигла могущества и достаточно полно обнаружила свою общественную природу. Из этого следует два вывода:

1. В эпоху Бэкона могли рождаться какие угодно иллюзии относительно общественного предназначения машин, и это было закономерно.
2. В эпоху Милля и Маркса техника показала свою действительную природу, а вместе с этим миновало время создания теоретических иллюзий, что и дало повод для противоположной оценки техники, создаваемой учеными.

Очень похожая ситуация складывается и в отношении к самой науке.

Когда-то Ф. Бэкон провозгласил целью науки увеличение власти человека над природой. Но такой взгляд на науку был сформулирован им в начале XVII в. (его «Новый органон» издан в 1620 г.), когда наука Нового времени еще только нарождалась и в этом виде позволяла строить о себе иллюзии, в том числе те, что связаны с увеличением власти человека над природой. С тех пор прошло много времени. Стало очевидным, что человек не просто увеличивает власть над природой, а делает это за счет другого человека, для чего использует разные фрормы повышения производительной силы труда, в том числе производительной силы научного труда.

Наука - одна из форм повышения производительной силы труда, она не существует сама по себе и не может быть свободной от общественной жизни. Более того, она находится на перекрестии человеческих интересов и сама является «перекрестием» этих интересов. Поскольку господствующая роль в общественной жизни теперь оказалась в руках частного собственника, наука не может существенно отличаться от других фрорм производительной силы - техники, рынка и разделения труда. Как инженеры, создающие технику, или управленцы, изобретающие «научную систему выжимания пота», так и ученые всюду работают на господствующий класс. И это происходит независимо от того, сознают они глубинные потребности частного собственника или не сознают, раскрывают перед людьми действительное содержание этой связи или глубоко упрятывают ее от общественности, бросают свои разработки на совершенствование производства или, наоборот, не участвуют в модернизации производства, перестраивают механизм формирования общественного сознания или не перестраивают [16]. Во всех случаях ученые получают ресурс господствующего класса и через этот ресурс влияют на ход развития общественной жизни, становятся интересными для господствующих классов, а взамен обретают условия более-менее благополучного существования самой науки.

Так уже было в истории науки. Лондонское королевское общество было создано в XVII в., оно объединило ученых в доброволь- 
ную организацию и приняло устав, санкционированный высшей государственной властью. При этом научное сообщество не ставило вопроса о коренной перестройке социальных ценностей и не пыталось навязать свои ценности всему обществу. Напротив, оно гарантировало обществу невмешательство в деятельность господствующих институтов, а государственные институты, в свою очередь, предоставили научному сообществу возможность спокойного выживания, ориентации ученых на широкое применение методов рационалистического мышления. Примерно то же самое сделала российская наука рубежа XX-XXI вв. Отечественные ученые согласились работать на российский капитал, а стратегической целью этого капитала является прибыль, получаемая, с одной стороны, за счет низкой стоимости рабочей силы, а с другой - за счет увеличения объемов добываемого сырья. С этой точки зрения различие между наукой Англии XVII в. и наукой России рубежа XX-XXI вв. несущественно. Оно заключается в том, что рационалистические методы английских ученых фрормировались в противовес традициям религиозного мышления, а российских - в противовес социалистически организованному мышлению. Другое дело - духовный скачок в Греции VI-V вв. до н. э. Он произошел в условиях, прямо противоположных тем, что сопровождали развитие науки в Англии и России. Греческие полисы создавали формы общественной жизни при максимальной активности народа, его самосознание требовало адекватных себе выразительных средств, и эти средства были найдены. Одно из них привело к возникновению научного знания, благодаря которому маленькая Эллада не только опередила более древние цивилизации Вавилона и Египта, но стала лидером народов средиземноморского бассейна.

\section{3. Выводы}

Из всего сказанного можно сделать четыре вывода:

1. Наука - одна из форм повышения производительной силы труда.

2. Наука не существует сама по себе, она не свободна от общества, поэтому деятельность ученых оказывается на перекрестии человеческих интересов и сама является «перекрестием» этих интересов.

3. Поскольку господствующий интерес сосредоточен теперь в руках частного собственника, современную науку необходимо определять как деятельность ученых, направленную на выработку и систематизацию знаний в понятийной форме, предназначенных для удовлетворения исторически конкретных потребностей класса частных собственников.

4. Ближайшим следствием такой деятельности ученых является то, что их разработки облегчают положение частных собственников, но не наемных работников. Обратной стороной этого процесса выступает ослабление интереса широкого населения к науке и капиталу. Правда, границы, разделяющие частных собственников и наемных работников, весьма относительны. Господствующий и подчиненные классы не «падают с неба», они вырастают из существующих производственных отношений; поэтому их взаимоотношения представляют собой предельное выражение воли и желаний всех социальных групп, занятых в производстве. И если подчиненные классы закрепляют бразды правления за господствующим, они тем самым признают, что сами подчиненные классы стремятся точно к такому же результату, что и господствующие классы, и потому они остаются довольными своим общественным положением даже в случае, если и не достигают уровня господствующего класса.

\section{СПИСОК ИСПОЛЬЗОВАННОЙ ЛИТЕРАТУРЫ}

1. Томпсон М. Философия науки : пер. с англ. / М. Томпсон. - М. : Фаир-Пресс, 2003. - 304 с.

2. Шноль С. Гении и злодеи российской науки: Иосиф Абрамович Рапопорт (1912-1990) [Электронный ресурс] / С. Шноль. - Режим доступа: http://www.rapoport-genetika.ru/content/statya-iz-knigi-simonashnolya-genii-i-zlodei-rossiyskoy-nauki-iosif-abramovich-rapoport.

3. Кузнецова Н. И. Наука в ее истории (методологические проблемы) / Н. И. Кузнецова. - М. : Наука, 1986. -128 c.

4. Рожанский И. Д. Античная наука / И. Д. Рожанский. - М. : Наука, 1980. - 200 с.

5. Рожанский И. Д. Анаксагор / И. Д. Рожанский. - М. : Мысль, 1983. - 144 с.

6. Рожанский И. Д. Анаксагор. У истоков античной науки / И. Д. Рожанский. - М. : Наука, 1972. - 320 с.

7. Рожанский И. Д. История естествознания в эпоху эллинизма и Римской империи / И. Д. Рожанский. М. : Наука, 1988. - 448 с.

8. Рожанский И. Д. Развитие естествознания в эпоху античности: ранняя греческая наука «о природе» / И. Д. Рожанский. - М. : Наука, 1979. - 488 с.

9. Бряник Н. В. Введение в современную теорию познания : учеб. пособие / Н. В. Бряник. - М. : Акад. проект ; Екатеринбург : Деловая кн., 2003. - 288 с. 
10. Бряник Н. В. История науки доклассического периода: фрилософрский анализ : учеб. пособие / Н. В. Бряник. - Екатеринбург : Изд-во Урал. ун-та, 2016. - 162 с.

11. Ильенков Э. В. Логическое и историческое / Э. В. Ильенков // Философрская энциклопедия : в 5 т. / гл. ред. В. Ф. Константинов. - М. : Сов. энцикл., 1964. - Т. 3. - 584 с.

12. Любищев А. А. Из переписки / А. А. Любищев // Пути в незнаемое : писатели рассказывают о науке / редкол.: А. 3. Анфиногенов [и др.]. - М. : Сов. писатель, 1978. - Вып. 14. - С. 397-423.

13. Советский энциклопедический словарь / гл. ред. А. М. Прохоров. - 2-е изд. - М. : Сов. энцикл., 1983. - 1600 с.

14. Маркс К. Немецкая идеология / / Сочинения : в 50 т. / К. Маркс, Ф. Энгельс. - 2-е изд. - М. : Госполитиздат, 1955. - Т. 3. - С. 7-544.

15. Маркс К. Капитал. Т. 1. Кн. 1: Процесс производства капитала / К. Маркс // Сочинения : в 50 т. / К. Маркс, Ф. Энгельс. - 2-е изд. - М. : Госполитиздат, 1960. - Т. 23. - 907 с.

16. Ткачев В. С. Идеалы русской интеллигенции. Сравнительный анализ общественной мысли России XVIII начала XX веков / В. С. Ткачев В. - Иркутск : Изд-во ИГЭА, 1998. - 229 с.

\section{REFERENCES}

1. Thompson M. Philosophy of Science. Hodder Headline Plc., 2001. 208 p. (Russ. ed.: Thompson M. Filosofiya nauki. Moscow, Fair-Press Publ., 2003. 304 p.).

2. Shnol' S. Genii i zlodei rossiiskoi nauki: losif Abramovich Rapoport (1912-1990) [Geniuses and Villains of the Russian Science: losif Rapoport (1912-1990)]. Available at: http: / / www.rapoport-genetika.ru /content/statyaiz-knigi-simona-shnolya-genii-i-zlodei-rossiyskoy-nauki-iosif-abramovich-rapoport. (In Russian).

3. Kuznetsova N. I. Nauka $v$ ee istorii (metodologicheskie problemy) [Science in its History (Methodological Issues)]. Moscow, Nauka Publ., 1986. 128 p.

4. Rozhanskii I. D. Antichnaya nauka [Ancient Science]. Moscow, Nauka Publ., 1980. 200 p.

5. Rozhanskii I. D. Anaksagor [Anaxagoras]. Moscow, Mysl' Publ., 1983. 144 p.

6. Rozhanskii I. D. Anaksagor. U istokov antichnoi nauki [Anaxagoras. The Dawn of the Ancient Science]. Moscow, Nauka Publ., 1972. 320 p.

7. Rozhanskii I. D. Istoriya estestvoznaniya $v$ epokhu ellinizma i Rimskoi imperii [History of Natural Sciences in the Hellenistic and Roman Empire Period]. Moscow, Nauka Publ., 1988. 448 p.

8. Rozhanskii I. D. Razvitie estestvoznaniya v epokhu antichnosti: rannyaya grecheskaya nauka "o prirode» [Natural Science Development in Classical Antiquity: the Early Greek Science on «Nature»]. Moscow, Nauka Publ., 1979. 488 p.

9. Bryanik N. V. Vvedenie $v$ sovremennuyu teoriyu poznaniya [Introduction to the Modern Epistemology]. Moscow, Akademicheskii proekt Publ.; Yekaterinburg, Delovaya kniga Publ., 2003. 288 p.

10. Bryanik N. V. Istoriya nauki doklassicheskogo perioda: filosofskii analiz [History of Pre-classic Science: Philosophical Analysis]. Yekaterinburg, Ural State University Publ., 2016. 162 p.

11. Il'enkov E. V. The Logical and the Historical. In Konstantinov V. F. (ed.). Filosofskaya entsiklopediya [Philosophical Encyclopedia]. Moscow, Sovetskaya entsiklopediya Publ., 1970. Vol. 3. 584 p. (In Russian).

12. Lyubishchev A. A. Selected Letters. In Anfinogenov A. Z. et al. (eds). Puti $v$ neznaemoe: pisateli rasskazyvayut o nauke [Ways to the Unknown: Writers about Science]. Moscow, Sovetskii pisatel' Publ., 1978, iss. 14, pp. 397-423. (In Russian).

13. Prokhorov A. M. (ed.). Sovetskii entsiklopedicheskii slovar' [Soviet Encyclopedic Dictionary]. $2^{\text {nd }}$ ed. Moscow, Sovetskaya entsiklopediya Publ., 1983. 1600 p.

14. Marx K., Engels F. German Ideology. In Marx K., Engels F. Sochineniya [Works]. Moscow, Gospolitizdat Publ., 1955, vol. 3, pp. 7-544. (In Russian).

15. Marx Karl. Das Kapital. Kritik der politischen Ökonomie. Erster Band. Buch 1: Der Produktionsprocess des Kapitale. Hamburg, Verlag von Otto Meissner, 1867. (Russ. ed.: Marx K., Engels F. Sochineniya [Works]. $2^{\text {nd }}$ ed. Moscow, Gospolitizdat Publ., 1960. Vol. 23. 907 p.).

16. Tkachev V. S. Idealy russkoi intelligentsii: Sravnitel' nyi analiz obshchestvennoi mysli Rossii XVIII - nachala $X X$ vekov [The Ideals of the Russian Intelligentsia: A Comparative Analysis of Social Thought in Russia in the $18^{\text {th }}-$ beginning of the $20^{\text {th }}$ Centuries]. Irkutsk State Academy of Economics Publ., 1998. $229 \mathrm{p}$.

\section{Информация об авторе}

Ткачев Валерий Сысоевич - доктор фиилософских наук, профессор, кафедра философии, Байкальский государственный университет, 664003, г. Иркутск, ул. Ленина, 11, e-mail: vl201548@yandex.ru.

\section{Для цитирования}

Ткачев В. С. Наука как общественное явление: определение науки и социальный характер деятельности ученых / В. С. Ткачев // Известия Байкальского государственного университета. - 2017. - T. 27, № 3. - C. 320-326. - DOI: $10.17150 / 2500-2759.2017 .27(3) .320-326$.

\section{Author}

Valerii S. Tkachev - DSc in Philosophy, Professor, Philosophy Department, Baikal State University, 11 Lenin St., 664003, Irkutsk, Russian Federation, e-mail: vl201548@yandex.ru.

\section{For Citation}

Tkachev V. S. Science as a Social Phenomenon: Definition of Science and Social Character of Scientific Activity. Izvestiya Baykal'skogo gosudarstvennogo universiteta $=$ Bulletin of Baikal State University, 2017 vol. 27 , no. 3, pp. 320-326. DOI: 10.17150/25002759.2017.27(3).320-326. (In Russian). 